\title{
PENGARUH DESAIN MUKA FASHION BATIK TERHADAP KUANTITAS PENJUALAN DI MALANG
}

\author{
Kiswandono $^{1)}$, Sri Indriani ${ }^{2)}$, Sony Haryanto ${ }^{3)}$ \\ ${ }^{1,2,3)}$ Prodi Teknik Industri, Fakultas Teknologi Industri, Institut Teknologi Nasional Malang
}

\begin{abstract}
Abstrak, Penelitian ini bertujuan untuk mengetahui pengaruh yang ditimbulkan desain muka fashion batik galeri outlet terhadap kuantitas penjualan di Malang dan mencari factor yang paling dominan berpengaruhnya dalam desain muka dan warna dalam kualitas penjualan. Berdasarkan penelitian ini terhadap busana perempuan dan laki untuk produk galeri outlet yang ada di Malang terhadap produk galeri outlet yang selama ini kurang memenuhi target dipasaran. Penelitian dilakukan dengan mengamati desain dan warna pada busana laki dan perempuan produk galeri Batik Malang. Hasil Pengujian Kuantitas Penjualan cara yang digunakan dengan menggunakan kuisoner dengan respoden penduduk kota Malang yang menjadikan konsumen produk tersebut. Dari Analisa yang dilakukan setelah memvariasikan bentuk desain dan warna dapat diketahui bahwa variasi desain dan warna tidak mempunyai pengaruh pada fashion secara signifikan. Dengan melakukan uji regresi dapat diketauhi bentuk dan warna tidak mempengaruhi kualitas penjualann. Dari regresi berganda dapat diketahui variable fashion desain batik yang paling mempengaruhi kuantitas penjualan.
\end{abstract}

Kata Kunci : Desain Fashion Batik, Kuantitas Penjualan

\section{PENDAHULUAN}

Industri tekstil di dunia berkembang terus menerus, hal ini menghasilan dunia pertekstilan yang geilang diantara kalanagan mode. Sebab apa pakaian telah mengarah ke teknologi yang lebih cerah. Bagaimanapun juga pakaian telah di usahakan dengan sungguh-sungguh untuk memperlihatan kekuasaannya, berlomba unuk keindahan dan melindungi dari panas dan dingin yang sangat hebat. Namun pada kenyataannya untuk menghasilkan busana yang berkualiatas bukan hal yang mudah, karena diperlukan keahlian atau kreatifitas tertentu untuk mencapai tersebut.

Indonesia telah memantapkan tekstil dan produk tekstil sebagi primadona komiditas ekspor nonmigasnya. Oleh karena itu, sepatutnya industri mode di Tanah Air yang dalam jumlah besar mengandung komponen tersebut didorong untuk berkembang secara maksimal. Berkembangnya industri mode Indonesia bergantung pada sumber daya manusianya yang berkulitas dan profesional.

Setia waktu produk tekstil selalu mengalami perubahan, utama dalam bidang garment yang di iringi dengan mode atau trend yang terus berkembang. GO mencoba menciptakan trend yang merupakan perpaduan antara keinginan konsumen dan produk yang disediakan. Penciptaan ternd yang diterima konsumen akan mengikat konsumen tersebut pada penjualnya. Oleh karena itu jangan heran bila trend yang di tawarkan masing-masing GO berbeda satu sama lain.

Desain pada suatu busana dapat mempegaruhi berbagi macam faktor dalam kuantitas pejualan, salah satunya adalah keaneragaman bentuk dan juga warna, dimana masing-masing faktor tersebut memiliki daya tarik yang berbeda. Secara umum, masing-masing fashion desain tersebut dapat dianalisa bedasarkan bentuk dan kombinasi warnanya pada batik. Tapi dalam hal ini bila model busana digunakan untuk fashion desain, diduga bahwa bentuk dan warna dapat berubah karena pengaruh trend yang diberikan. Faktor-faktor ini menjadi faktor penting yang digunakan oleh konsumen dalam memilih produk GO yang akan digunakan. Model melibatkan berbagai kemampuan agar desain tesebut dapat tampil indah, bertahan lama, berfungsi, mudah digunakan, dengan harga terjangkau dan ekonomis. Hal tersebut membutuhkan keseluruhan keahlian yang dimiliki pendesainnya.

Dunia desain busana batik beraneka ragam. Kegiatan dapat melalui busana seri siap pakai, busana unik, busana seni, adhi busana dan lain-lainnya. Bidang usha pun 
beraneka ragam, yang dapat merupakan konfeksi, modiste atau jahitan khusus.

\section{METODE}

Pengumpulan data dalam penelitian ini mengguanakan beberapa metode agar keseluruhan prosedur yang dilalui dapat dilaksanakan dengan teratur. Metode-metode tersebut adalah sebagi berikut:

1. Obserbasi Lapangan

Adalah cara mengumpulkan data melalui proses pengaman secara langsung terhadap obyek yang diteliti dan dilanjutkan dengan pencatatan data kuantitatif,

2. Metode Angket atau Kuesioner

Merupakan teknik pengumpulan data dengan mendistribusikan daftar pertanyaan untuk diisi dan dikembangkan kepada peneliti untuk dianalisis lebih lanjut. Kuesioner dibuat dengan bahasa yang sederhana, pertanyaan dan pilihan jawaban yang singkat dan jelas, serta mudah dimengerti oleh responden yang berasal dari berbagai kalangan.

\section{Rancangan Penelitian}

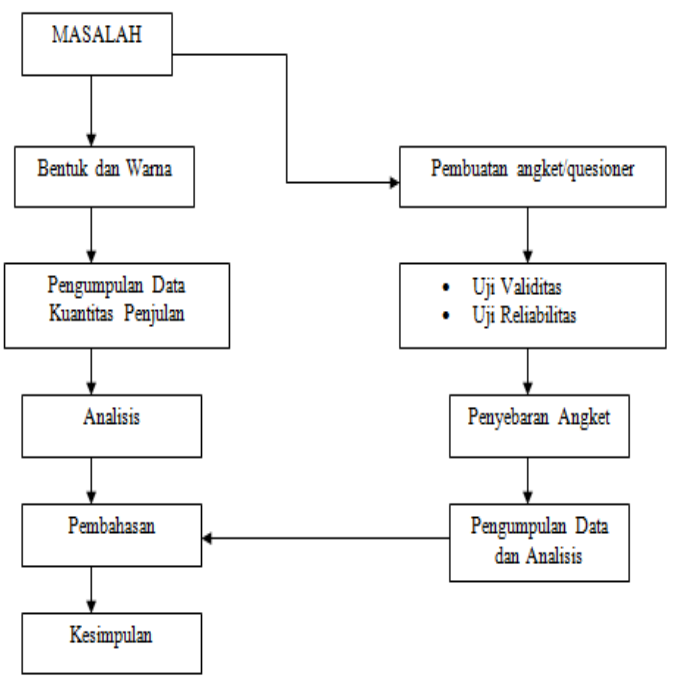

\section{HASIL DAN PEMBAHASAN}

Secara umum mengetahui seberapa besar responden tentang desain muka fashion batik. Responden konsumen yang ingin kita ketahui secara garis besar meliputi :

1. Responden Desain Muka Batik Perempuan dan Laki Laki.

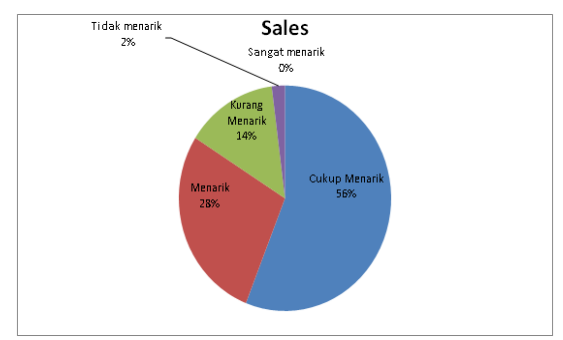

Gambar 1. Diagram Presentase Responden Tentang Desain Muka Batik

2. Responden Tentang Penggunaan Produk Galeri Outlet Suatu Kebiasaan

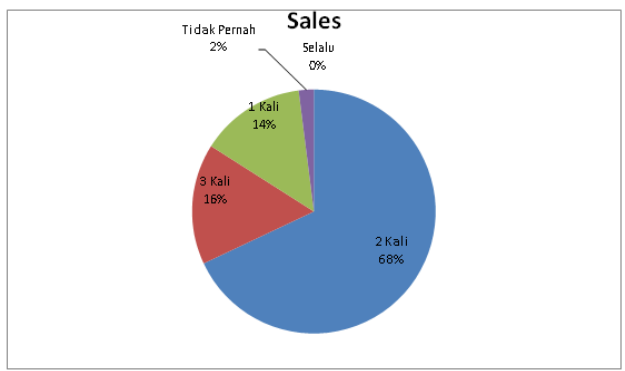

Gambar 2. Diagram Presentase Tentang Penggunaan Produk Galeri Outlet Suatu Kebiasaan.

\begin{tabular}{|c|c|c|c|c|c|c|c|c|}
\hline 10 & 3 & 2 & 4 & 2 & 22 & 14 & 19 & 1 \\
\hline 11 & 1 & 1 & 3 & 2 & 22 & 18 & 13 & 2 \\
\hline 12 & 1 & 2 & 3 & 1 & 18 & 13 & 20 & 5 \\
\hline 13 & 2 & 3 & 3 & 2 & 19 & 16 & 16 & 3 \\
\hline 14 & 3 & 1 & 3 & 2 & 18 & 20 & 17 & 1 \\
\hline 15 & 2 & 4 & 3 & 2 & 22 & 19 & 17 & 4 \\
\hline 16 & 3 & 3 & 4 & 1 & 10 & 20 & 13 & 1 \\
\hline 17 & 1 & 3 & 4 & 2 & 17 & 16 & 17 & 5 \\
\hline 18 & 1 & 3 & 3 & 1 & 13 & 17 & 23 & 1 \\
\hline 19 & 3 & 1 & 5 & 2 & 14 & 18 & 19 & 5 \\
\hline 20 & 3 & 2 & 4 & 2 & 17 & 15 & 17 & 2 \\
\hline 21 & 3 & 2 & 2 & 1 & 19 & 19 & 17 & 4 \\
\hline 22 & 2 & 1 & 3 & 1 & 14 & 15 & 18 & 5 \\
\hline
\end{tabular}

3. Respond Keberadaan Produk Galeri Outlet Batik Saat Ini 


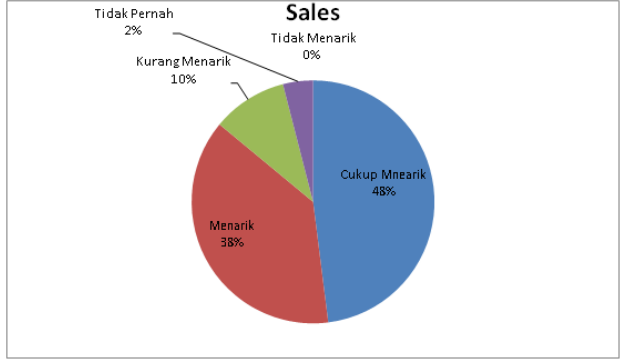

Gambar 3. Diagram Tentang Respond

Keberadaan Produk Galeri Outlet Batik Saat Ini.

\begin{tabular}{|c|c|c|c|c|c|c|c|c|}
\hline $\begin{array}{c}|c| \\
0\end{array}$ & \multicolumn{2}{|c|}{ IDENTITAS } & $\begin{array}{c}\text { BENTUK DAN } \\
\text { DESAN } \\
\text { PRODUK (X1) }\end{array}$ & $\begin{array}{c}\text { KUANTITAS } \\
\text { PENJUALAN (Y) }\end{array}$ & $\begin{array}{c}\text { WARNA } \\
\text { PRODUK (X2) }\end{array}$ & ATRIBUT LAIN \\
\hline 1 & 2 & 2 & 3 & 1 & 18 & 17 & 14 & 4 \\
\hline 2 & 3 & 5 & 2 & 1 & 13 & 15 & 13 & 3 \\
\hline 3 & 5 & 5 & 4 & 1 & 17 & 17 & 17 & 5 \\
\hline 4 & 3 & 3 & 4 & 2 & 18 & 19 & 16 & 5 \\
\hline 5 & 1 & 2 & 5 & 1 & 16 & 20 & 20 & 1 \\
\hline 6 & 2 & 3 & 4 & 2 & 13 & 15 & 19 & 2 \\
\hline 7 & 1 & 3 & 4 & 3 & 16 & 15 & 21 & 1 \\
\hline 8 & 2 & 3 & 3 & 1 & 18 & 15 & 16 & 3 \\
\hline
\end{tabular}

\section{Pembahasan analisa kuesioner}

Analisa kuisoner pengaruh fashion desain muka batik gallery outlet terhadap kuantitas penjualan. Hasil Uji regresi dimana harga $\mathrm{F}$ hitung $=27,48$ dan $\mathrm{F}$ table 3,1951 maka dapat disimpulkan model regresi yang dihasilkan signifikan kedua variable terhadap kuantitas penjulalan. Hasil Uji $\mathrm{T}$ untuk mengetahui masing masing mempengaruhi variable kuantitas penjualan dimana variable yang paling dominan yang mempengarui terhadap kuantitas penjualan adalah bentuk dan model busana laki maupun busana perempuan pada gallery outlet tersebut. Dari hasil ui $\mathrm{T}$ tersevut secara parsial variable bentuk dan model dan warna busana wanita dan busana pria pada gallery outlet berpengaruh signifikan pada kuantitas penjualan. $\mathrm{Y}=2,956+0,382 \mathrm{X} 1+0,413 \mathrm{X} 2$

Persamaan diatas menunjukan adanya hubungan positif antara kuantitas penjualan dengan bentuk/model dan warna busana wanita laki gallery outlet. Artinya setiao tambahan 1 unit bentuk dan model busana wanita/laki produk galleryoutlet akan meningkat kuantitas penjualnya sebesar 0,382 dan setiap penambahan 1 nilai warna busana galeri akan meningkat kuantitas penjualan sebesar 0,413

Koefisien determinasi menunjukan kemampuan model regresi dalam variable $\mathrm{R}$ dihasilkan sebesar $53,9 \%$ variable bentuk dan model dan warna busana wanita/laki gallery outlet terhadap kuantitas penjualan sebesar $53,9 \%$ sedangkan sisanya sebesar 46,1 dipengaruhi oleh variable lainnya.

\begin{tabular}{|l|c|c|c|c|c|c|c|c|}
\hline 23 & 3 & 5 & 2 & 1 & 20 & 18 & 20 & 3 \\
\hline 24 & 1 & 4 & 3 & 1 & 21 & 15 & 22 & 2 \\
\hline 25 & 4 & 1 & 4 & 2 & 14 & 23 & 12 & 4 \\
\hline 26 & 3 & 2 & 4 & 2 & 20 & 19 & 14 & 5 \\
\hline 27 & 2 & 4 & 5 & 2 & 13 & 17 & 19 & 1 \\
\hline 28 & 3 & 3 & 3 & 1 & 21 & 16 & 18 & 2 \\
\hline 20 & 2 & 3 & 3 & 1 & 20 & 17 & 19 & 4 \\
\hline 30 & 1 & 3 & 3 & 1 & 19 & 18 & 20 & 5 \\
\hline
\end{tabular}

\section{Kesimpulan}

Dapat disimpulkan variable desain muka batik dapat mempengaruhi kuantitas penjualan adapun hasil yang didapat bentuk model busana wanita dan laki produk galeri outlet memiliki pengaruh yang lebih tinggi dibandingkan dengan warna yang ada pada busana wanita laki produk gallery outlet.

Hasil pehitungan kuisoner dapat diketahui bahwa sebagian besar penduduk kota Malang selalu tertarik dengan busana wanita maupun laki produk gallery outlet. Sedangkan adapun 
factor lain yang mempengaruhi daripada kuantitas penjualan.

\section{HASIL DAN PEMBAHASAN}

Produsesn busana wanita laki gallery outlet lebih banyak melakukan inovasi dan kreativitas dari terhadap busana galley outlet tersebut tanpa mengubah struktur yang dapat mempengaruhi nilai status social gallery outlet itu sendiri dan lebih banyak melakukan pengenalan terhadap masyarakat tentang produk produk baru.

Produsen galleri outlet diharapkan dapat mempertahankan kualitas dan model yang lebih baik dan harga yang lebih terjangakau

\section{DAFTAR PUSTAKA}

Arikunto, Suharismi, 2002, Prosedur Penelitian, Rineka Cipta, Jakarta.

Boyd, Walker, Larreche, 2000, Manajemen Pemasaran, Edisi 2, Erlangga, Jakarta.
Chodijah \& Alim Zaman, 2001, Desain Mode Tingkat Dasar, Meutia Cipta Sarana, Jakarta

Kotler, Philkip, 2002, Manajemen Pemasaran, Volume I, Edisi 10, PT. Prehallindo, Jakarta

Murshid, M, 2003, Mode Busana, Kanasius, Yogyakarta

Rahmat, Jalalludin, 2002, Metode Penelitian Komunikasi, PT. Remaja Rosda Karya Offset, Bandung

Sachari, Agus, 1999, Tinjuan Historis Desain Modern, Balai Pustaka, Jakarta.

Sugiyono, 2000, Statistik Untuk Penelitian, Alfabeta, Bandung

Supiyono, R.A, 1985, Manajemen Strategi Dan Kebijaksaaan Bisnis, BPEE, Jogyakarta.

Singarimbun, Masri \& Effendi Sofian, (ed), 1999, Metode Penelitian Survai, LP3ES

Universitas Negeri Malang, 2000, Pedoman Penulisan Karya 